\title{
A quick earthquake disaster loss assessment method supported by dasymetric data for emergency response in China
}

\author{
Jinghai $\mathrm{Xu}^{1}$, Jiwen $\mathrm{An}^{2}$, and Gaozong $\mathrm{Nie}^{2}$ \\ ${ }^{1}$ College of Geomatics Engineering, Nanjing Tech University, Nanjing, China \\ ${ }^{2}$ Institute of Geology, China Earthquake Administration, Beijing, China \\ Correspondence to: Gaozong Nie (niegz@ies.ac.cn) \\ Received: 23 December 2014 - Published in Nat. Hazards Earth Syst. Sci. Discuss.: 19 February 2015 \\ Revised: 15 March 2016 - Accepted: 21 March 2016 - Published: 1 April 2016
}

\begin{abstract}
Improving earthquake disaster loss estimation speed and accuracy is one of the key factors in effective earthquake response and rescue. The presentation of exposure data by applying a dasymetric map approach has good potential for addressing this issue. With the support of $30^{\prime \prime} \times 30^{\prime \prime}$ areal exposure data (population and building data in China), this paper presents a new earthquake disaster loss estimation method for emergency response situations. This method has two phases: a pre-earthquake phase and a co-earthquake phase. In the pre-earthquake phase, we precalculate the earthquake loss related to different seismic intensities and store them in a $30^{\prime \prime} \times 30^{\prime \prime}$ grid format, which has several stages: determining the earthquake loss calculation factor, gridding damage probability matrices, calculating building damage and calculating human losses. Then, in the co-earthquake phase, there are two stages of estimating loss: generating a theoretical isoseismal map to depict the spatial distribution of the seismic intensity field; then, using the seismic intensity field to extract statistics of losses from the pre-calculated estimation data. Thus, the final loss estimation results are obtained. The method is validated by four actual earthquakes that occurred in China. The method not only significantly improves the speed and accuracy of loss estimation but also provides the spatial distribution of the losses, which will be effective in aiding earthquake emergency response and rescue. Additionally, related pre-calculated earthquake loss estimation data in China could serve to provide disaster risk analysis before earthquakes occur. Currently, the precalculated loss estimation data and the two-phase estimation method are used by the China Earthquake Administration.
\end{abstract}

\section{Introduction}

Earthquakes are one of the most serious natural disasters in the world. For example, the 1994 Northridge earthquake in the USA caused USD 12.5 billion in insurance losses (NRC, 1999), the Bam earthquake in Iran (2003) resulted in more than 30000 deaths (Nadim et al., 2004), while 69227 people died and 17923 people were missing in the Wenchun earthquake in China (2008) (China Earthquake Administration, 2010). Unfortunately, accurate earthquake prediction is still a difficult and at times even impossible task. In such situations, post-earthquake emergency response and rescue services have been used in many real earthquake scenarios to mitigate the disaster in China. These have already proven their efficiency many times in earthquake disaster mitigation (Earthquake Emergency Rescue Department, 2004). Many earthquake rescue operations have shown how prompt and correct decision-making about rescue actions is crucial for success. Since after $72 \mathrm{~h}$ following an earthquake the survival rate of people buried in destroyed buildings sharply decreases, this period after an earthquake has been known as the "golden" $72 \mathrm{~h}$ (Xu et al., 2013). Generally, after a destructive earthquake, it is necessary to bring in rescue teams from outside the disaster area, often taking considerable time (generally more than 2 days) for them to gather, and to be dispatched to the stricken areas, especially in mountainous areas.

Quick and effective rescue decision-making is based on understanding the available disaster information, even if it is not very accurate. However, there is a "black-box effect" of disaster information in the co-earthquake period ( 0 to $1 \mathrm{~h}$ after an earthquake), which means it is almost impossible to 
obtain useful disaster information within the first 1 to $2 \mathrm{~h}$ after an event (Nie et al., 2012). As an alternative, descriptive earthquake parameters (i.e. earthquake magnitude, peak ground acceleration - PGA) have been used as inputs to estimate the possible losses and to provide emergency disaster information, where possible building damage and loss of life are the most important factors.

China is a country that suffers from serious earthquake disasters. Due to its large land territory and high population, the Chinese government has very high real-time requirements for co-earthquake disaster loss estimation (especially human loss). Generally, it takes only $30 \mathrm{~min}$ for experts from the China Earthquake Administration (CEA) to estimate the potential losses and to prepare suggestions for the rescue countermeasures (Miao and Nie, 2004). Even for a huge earthquake like the Wenchuan earthquake $\left(M_{\mathrm{S}}=8.0\right)$, the first earthquake loss estimation and rescue countermeasures have to be submitted to the central government within $1 \mathrm{~h}$ of the earthquake. However, performing the current earthquake disaster loss estimation methods used by the CEA needs more than $20 \mathrm{~min}$, not including the time for preparing the rescue countermeasure suggestions and other unexpected actions. Moreover, sometimes the accuracy of the estimation results is not correct to an order of magnitude compared to real disaster information. This has even delayed and misled the rescue decision-making in the response to China's Wenchuan earthquake. For example, one of most severely affected areas, Qinchuan County, did not get an appropriate rescue response, while most of rescue materials were sent to the less damaged Dujiangyan City. One of the reasons for this problem is that the disaster exposure data (population, buildings) are based on administrative units (census tracts).

A dasymetric map approach considers the spatial disparity of disaster exposure data and can improve the disaster estimation accuracy (Chen et al., 2004). With the support of our former project ("Earthquake Emergency Foundation Data Spatialization and Regional Emergency Response Ability Estimation"), a dasymetric exposure data set (including population and buildings) has been developed. This study is focused on using these dasymetric data to improve the speed and accuracy of co-earthquake disaster loss estimation (building damage and human losses). This research work is part of the National Key Technology R \& D Programme of China entitled, "Earthquake Disaster Information Service and Emergency Decision-making Support Platform". The project aims to develop rapid disaster information estimation and collection methods and to dynamically generate emergency countermeasures for all levels of government.

The remainder of this paper is organised as follows: Sect. 2 presents research related to the study; Sect. 3 introduces the areal exposure data that will be used in this study, including population and building data covering the whole of China; Sect. 4 presents a two-phase earthquake disaster loss estimation method based on areal exposure data, consisting of the pre-earthquake phase and co-earthquake phase; Sect. 5 uses four real earthquake cases to validate the speed and accuracy of the loss estimation using this method and discusses the results; and Sect. 6 sets out the conclusions of this study.

\section{Related research}

Earthquake disaster loss estimation and risk analysis are key components of disaster management. Considering spatial range, earthquake damage estimation models can be classified into globally used and locally used types. The globally used model tries to estimate the earthquake disasters occurring all over the world. A Prompt Assessment of Global Earthquakes for Response (PAGER) system has been developed by the US Geological Survey (USGS) to rapidly estimate the deaths and economic losses from earthquakes (http: //earthquake.usgs.gov/earthquakes/pager/). This system can report economic losses and the number of affected people and the risk level within $30 \mathrm{~min}$ of a significant earthquake (magnitude greater than 5.5). However, because of the spatial variability of the ground motion, the estimated disaster loss accuracy is reduced by inaccurate information on the shaking caused by the event (Karimzadeh et al., 2014). Similar global (regional) systems include the Global Disaster Alert and Coordination System (GDACS; http://www.gdacs.org) and the World Agency of Planetary Monitoring and Earthquake Risk Reduction (WAPMERR; http://www.wapmerr.org). In addition, the Global Earthquake Model (GEM; http://www. globalquakemodel.org) aims to provide software and tools for seismic risk assessment and loss estimation through a worldwide public-private partnership.

Generally, because earthquake loss estimation is a complex issue, different methods and parameters are needed for different areas of the world (Karimzadeh et al., 2014). Several local earthquake loss methods have been developed. Hazards United States Multi-Hazard (HAZUS-MH) is a well-known system (model) developed by Federal Emergency Management Agency (FEMA) in the USA. It can be used for multiple categories of natural disasters, including earthquakes. HAZUS-MH uses a building fragility curve to estimate possible damage, which is supported by census tract data. However, it is a time-consuming system. The preparation of rapid loss estimates for large study regions of $1000-2000$ census tracts might require 0.5 to $1.5 \mathrm{~h}$ of analysis time (FEMA, 2003). The Karmania hazard model is another GIS (Geographic Information System)-based local earthquake disaster loss estimation method developed in Iran (Hassanzadeh et al., 2013). Based on census tract exposure data, this model can be used to compute the damage to buildings and human losses caused by earthquakes and to assess the resources needed after an earthquake event.

Concerning the disaster estimation methods, many studies have focused on building damage estimation. However, human loss information is more important for earthquake emergency responses. Different levels of human loss mean dif- 
ferent response and rescue levels, according to the Chinese Earthquake Emergency Response Plan (http://www.gov.cn/ yjgl/2012-09/21/content_2230337.htm). And actual earthquake disaster loss investigations during the twentieth century have revealed that $75 \%$ of deaths come from building damage (Coburn and Spence, 2002). So generally, human losses are estimated by regression on building damage estimates. With regard to building damage estimation, two kinds of method are widely used: the damage probability matrices (DPM) method and the fragility curve method. Whitman et al. (1973) first suggested the use of DPM to describe the building damage probability in earthquakes and first adopted by the Applied Technology Council (ATC-13) in 1985 (ATC, 1985). This method first classifies buildings into 36 types and this was later reduced to 6 types in ATC-21 (Mocormack and Rad, 1997). In this method, the building damage is classified into five categories: no damage, slight damage, moderate damage, serious damage and collapse. The building damage ratio for different damage degrees (e.g. slight damage, moderate damage) under different seismic intensities are presented as a matrix of the area struck by an earthquake. The fragility curve method is actually the transformed DPM, which use a fragility curve to represent the possible damage related to ground movement parameters.

There are three general approaches to obtain an appropriate DPM or building fragility curve: an empirical approach, an analytic approach and a hybrid approach. The empirical approach is based on statistics of actual earthquake building damages and the setting up of a relationship between earthquake parameters (i.e. PGA, seismic intensity) and the degree of building damages (Anagnos et al., 1995). In the analytic approach, the DPM (or the building fragility curve) is derived from the mechanical analytic calculations for different types of building (Dymiotis et al., 1999). The hybrid approach simultaneously uses seismic hazard investigation data and building structure simulation analysis data to generate the DPM (or building fragility curve; Kappos et al., 2006).

Nowadays, the application of GIS is a growing trend and even a requirement for building damage estimation. GIS is widely used to manage and analyse disaster exposure data, which greatly improves the efficiency of use of such data (Mebarki et al., 2014; Panahi et al., 2014; Armenakis, 2013; Alam et al., 2013). The organization of the exposure data in a GIS has been found to significantly improved loss estimation speed and accuracy. Chen et al. (2004) and Thieken et al. (2006) elaborated the possible improvement in disaster loss analysis that can be obtained by the application of a dasymetric mapping approach in theory (more details on how this approach can be applied are provided in Fig. 8). As one of measures of exposure, there are many discussions about the production of areal population data (i.e. population distribution maps). Jia et al. (2014) used the dasymetric approach to disaggregate population census data into a quadrilateral grid composed of $30 \mathrm{~m} \times 30 \mathrm{~m}$ cells covering Alachua County, Florida. Alahmadi et al. (2013) produced a downscale population distribution of Riyadh, Saudi Arabia, using remote sensing data and ward-level census population data. According to Thieken et al. (2006), there are four categories of methods for generating population dasymetric map using land cover data: the binary method, three-class method, limiting variable method and regression method. All of these methods consider the spatial distribution of the population to be determined by the land use type. The binary method just considers one land use type, such as "urban area", while the three-class method selects three land use types (for example, urban, forest and agricultural types) for analysis. The limiting variable method considers all land use types in an areal unit and gives each land use type a threshold population. For example, maximal population 50 is set to land use type "urban area" in each kilometre grid. In the regression method, all the land use types are considered and their weights are determined by regression analysis.

In addition to dasymetric map generation modelling studies, there are already some well-known areal data sets of the world's population, such as the Gridded Population of the World (GPW; Balk and Yetman, 2004), the Global Rural Urban Mapping Project (GRUMP; CIESIN, 2004), the LandScan Global Population Databases (Dobson et al., 2000) and the WorldPop project (http://www.worldpop.org.uk/). The spatial scales generally range from $30^{\prime \prime}$ cells (about $1 \mathrm{~km}$ at the equator) to $7.5^{\prime \prime}$ cells (about $250 \mathrm{~m}$ ). In general, studies have focused on algorithms for generating the dasymetric maps and the improving of spatial resolution (Langford, 2007; Martin, 2011; Lin et al., 2011; Dmowska and Stepinski, 2014). Most studies have acknowledged the promising potential for applying these maps in disaster risk analysis and mitigation (Chakraborty et al., 2005).

By integrating the above studies and using areal exposure data, we will explore an earthquake disaster loss assessment method for application to the Chinese mainland earthquake emergency response, with the aim of improving the speed and accuracy of estimation.

\section{The input data}

\subsection{Data sets}

Exposure data sets are the foundation of any disaster loss estimation. From the perspective of earthquake emergency in China, these data have been named "earthquake emergency foundation data", which refers to the comprehensive data for earthquake disaster response and rescue, including a wide range of social, economic, population, city map, natural geographic landforms, key object location, rescue team information, relief communication and earthquake preplanning data (Nie et al., 2002). Over the last 10 years, much progress has been made in the construction of earthquake emergency foundation databases. Currently, each Chinese province has built an earthquake emergency foundation database. Earth- 
quake emergency foundation data gridding is the developing trend, disaggregating from administration units to areal grids, with the most popular representation of the data being the $30^{\prime \prime} \times 30^{\prime \prime}$ cell size (we abbreviate this to kilometre grid).

With the support of the project "Earthquake Emergency Foundation Data Spatialization and Regional Emergency Response Ability Estimation", the Institute of Geology, CEA, and the Institute of Geographic Sciences and Natural Resource Research, Chinese Academy of Sciences (CAS), jointly developed an earthquake emergency foundation data set in kilometre grid format in 2010.

In 2013, the data set was updated with the census data of the year 2011. The data set covers the Chinese mainland in its spatial range and has 20 thematic features, such as population, building and GDP. For this study, our aim was earthquake loss assessment, including the estimation of building damage and deaths; therefore, only the kilometre grid format of the population data (Fig. 1a) and building data (Fig. 1be) were used in this study, as shown in Fig. 1. The buildings were categorised into four types:

- B1 type buildings (see Fig. 1b): steel and steel reinforced concrete structures, i.e. high-rise steel structure, frame-shear wall structure, high-rise shear wall structure and multi-storey frame or high-rise frame structure. This type of building has the best anti-seismic capacity.

- B2 type buildings (shown in Fig. 1c): brick masonry structure; this type of structure is widely used in Chinese cities, its anti-seismic capacity is inferior to B1 type buildings.

- B3 type building (shown in Fig. 1d): brick house, openspace structure with $24 \mathrm{~mm}$ brick, cavity brick wall structure. Its anti-seismic capacity is inferior to B2 type buildings.

- B4 type building (shown in Fig. 1e): adobe houses mostly in Chinese rural villages. They have the worst anti-seismic capacity.

\subsection{Dasymetric model for the data set generation}

The data generation methods of this study are essentially a kind of regression method and are published in Chen et al. (2012), Han et al. (2013) and Jiang et al. (2002). In this paper, we take population data as an example to summarise the dasymetric data generation process, as described in the following steps.

- Dividing regions for modelling: as the Chinese territory is large, the model for dasymetric data generation (disaggregating administration unit data to grid data) in different regions (i.e. province, city, county) should be defined separately. However, it would be too complicated to build a unique model for each region. As the source population census data used in the study are based on the county level, we select county as the basic modelling unit. We build 40 model regions from 2861 counties, according to their geographic and population characteristics, such as population number, form and economy. In the modelled region, some typical counties (i.e. different average population density, different land use) have been sampled for regression analyses.

- Selecting parameters for the model: land use/land cover (LULC) data are widely used as auxiliary data (parameters) for dasymetric data generation (Thieken et al., 2006; Jia et al., 2014). We also use a similar method to build the dasymetric model, in which the land use data are divided into 60 categories from Landsat TM images. Then, the following six land use types are selected as the model parameters as they are considered to have the highest relevance to population distribution: cultivated land, forest land, grass land, rural residential land, urban residential land, industrial and transportation land (Jiang et al., 2002).

- Building the model: a linear regression method is used to build the model as shown in Eqs. (1) and (2). The relationship between population density and different types of land use is built in Eq. (1):

$P_{j}=\sum_{i=1}^{M}\left(p_{i j} \times s_{i j}\right)+B_{j}$,

where $P_{j}$ is the total population in a county $j, p_{i j}$ is average population density of the land use type $i$ in the county $j, s_{i j}$ is the area of the land use type $i$ in the county $j$ and $M$ is the land use type count. $p_{i j}$ and $B_{j}$ are the regression parameters, which are solved by least minimum square according to sample county data.

Then the population density in each grid can be calculated from Eq. (2):

$$
G_{k}=\frac{\sum_{i=1}^{M}\left(p_{i k} \times s_{i k}\right)}{\sum_{i=1}^{M} s_{i k}},
$$

where $G_{k}$ is the population density in a kilometre grid of the model region $k, p_{i k}$ is the average population density of the land use type $i$ in the grid, determined by Eq. (1), $s_{i k}$ is the area of the land use type $i$ in the grid and $M$ is the land use type count.

\section{Two-phase earthquake disaster estimation method supported by kilometre grid format exposure data}

Our estimation method consists of two phases: a preearthquake phase and a co-earthquake phase, as shown in 



Figure 1. Exposure data in kilometre grid format: (a) population data; (b) B1 type buildings (steel and steel reinforced concrete structure); (c) B2 type buildings (brick masonry structure); (d) B3 type buildings (brick house, open-space structure with 24 mm brick, cavity brick wall structure); (e) B4 type buildings (adobe houses mostly in Chinese rural villages).

Fig. 2. The pre-earthquake phase aims at pre-calculating earthquake losses according to earthquake description parameters (seismic intensity) and storing the pre-calculated loss estimation data in the database. Then, when an earthquake occurs, the disaster estimation becomes the extraction from the pre-calculated loss estimation data with regards to the spatial extent of the affected area and associated resulting intensity.

In the pre-earthquake phase, there are three stages: firstly, the seismic intensity is selected as the earthquake disaster loss calculation factor; then the human losses are calculated corresponding to each intensity value ranged from VI 


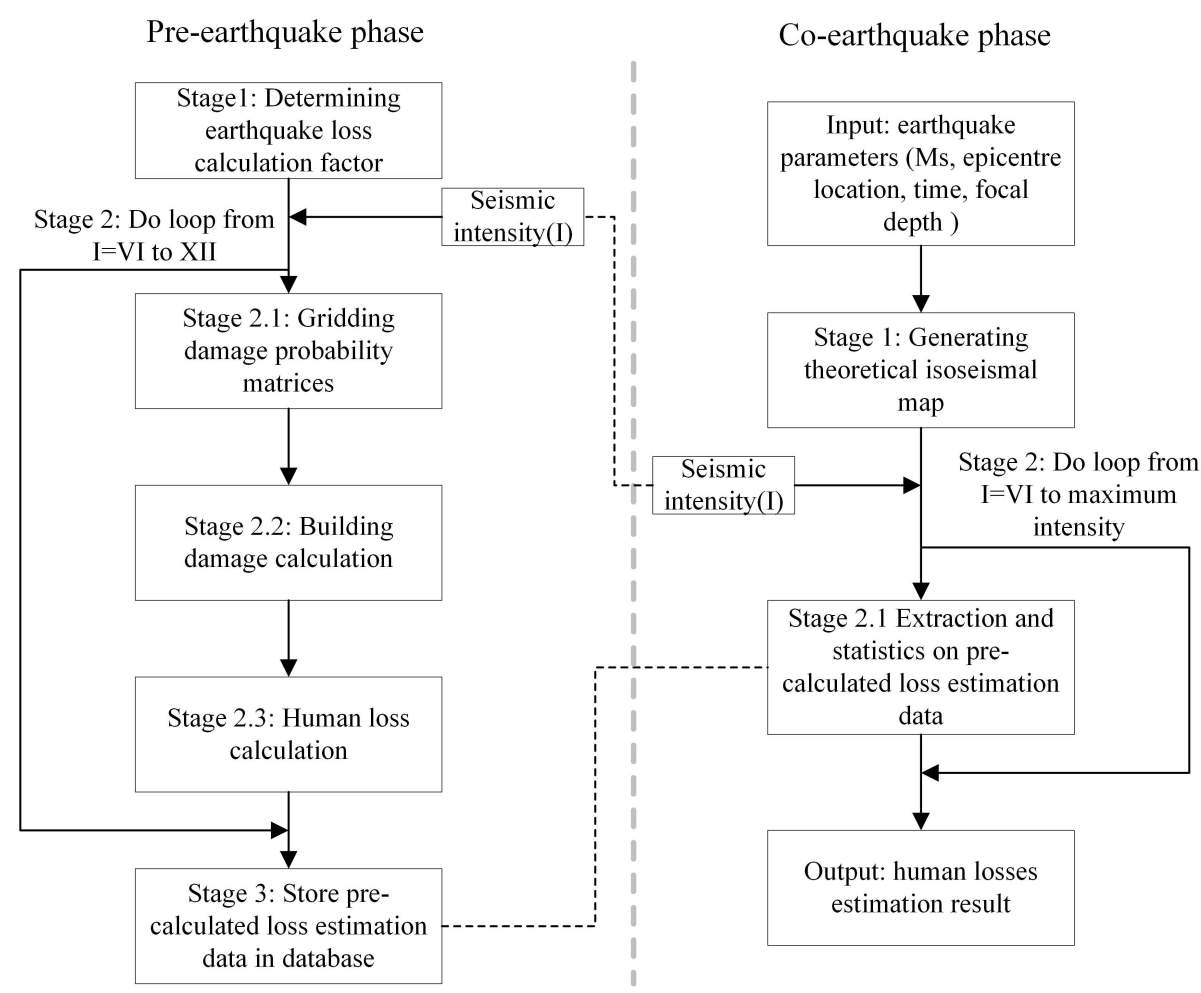

Figure 2. Components and workflow of the two-phase earthquake disaster loss estimation method.

to XII; finally the pre-calculated loss estimation data are stored in the database. In the co-earthquake phase, the following stages are used to estimate disaster loss. First, the earthquake parameters are retrieved from the Chinese nationwide earthquake monitor network. Then, according to these parameters, the theoretical isoseismal map (see Sect. 4.2.1) will be generated which depicts the seismic intensities distribution of the earthquake. These seismic intensities are then used to extract the pre-calculated disaster loss data from the database. The final result of the disaster loss estimation can thus be obtained from the statistics of the extracted data.

\subsection{Pre-earthquake phase}

\subsubsection{Determination of earthquake losses calculation factor}

Describing earthquake ground motion for disaster loss estimation may use several parameters: for example, surface wave magnitude $\left(M_{\mathrm{s}}\right)$, PGA, shake maps (i.e. a map showing the spatial distribution of some ground motion parameter) and spectral displacement (Eleftheriadou and Karabinis, 2011). Two factors were considered when we define the calculation parameters of this study.

1. Availability: as the primary objective of our investigation is to estimate earthquake disaster loss for the purposes of emergency response, the parameters sought for describing ground movement should be available in the co-earthquake period for the whole Chinese territory. As a nationwide earthquake monitoring network has been established by CEA. It can acquire four elements of data about any earthquake (epicentre location, time, magnitude, focal depth) within several minutes after its occurrence. Herein magnitude is expressed by $M_{\mathrm{s}}$, not PGA, shake map or other parameters. Publishing these four earthquake elements is the official job of CEA. Since the data on the four earthquake elements are released by a government department (CEA), this guarantees their authority and availability at any time for comparison with other ground movement parameters. They are also the Chinese national standards to describe an earthquake event. Hence, we primarily considered selecting them as the earthquake disaster loss calculation factors.

2. Accuracy: although the disaster loss is highly related to the four earthquake elements (especially earthquake magnitude), these elements are too coarse to directly use for loss estimation. Magnitude $\left(M_{\mathrm{S}}\right)$ usually represents the earthquake energy released, and the energy released is greater, the $M_{\mathrm{S}}$ is higher. However, high $M_{\mathrm{s}}$ may not directly cause high human losses. In earthquake engineering, seismic intensity is often used to mark the exposure damage, which indicates the local effects and potential for damage produced by an earthquake. So we finally selected this parameter as the disaster calculation factor for earthquake emergency disaster loss assess- 
Table 1. DPM of B1-type buildings in a seismic zone VI and VII (\%) (adapted from Yin, 1995).

\begin{tabular}{|c|c|c|c|c|c|c|c|c|c|c|c|}
\hline \multicolumn{6}{|c|}{ (a) DPM in a seismic zone VI } & \multicolumn{6}{|c|}{ (b) DPM in a seismic zone VII } \\
\hline$I$ & $N$ & $\mathrm{Sl}$ & $M$ & $\mathrm{Se}$ & $C$ & $I$ & $N$ & Sl & $M$ & $\mathrm{Se}$ & $C$ \\
\hline VI & 85 & 15 & 0 & 0 & 0 & VI & 88 & 12 & 0 & 0 & 0 \\
\hline VII & 60 & 35 & 5 & 0 & 0 & VII & 75 & 23 & 2 & 0 & 0 \\
\hline VIII & 40 & 36 & 21 & 2.5 & 0.5 & VIII & 55 & 33 & 10.3 & 1.5 & 0.2 \\
\hline IX & 20 & 0.37 & 28 & 12.5 & 2.5 & IX & 35 & 30.5 & 25.5 & 7.5 & 1.5 \\
\hline$X$ & 10 & 15.5 & 39.5 & 25.5 & 9.5 & $X$ & 15 & 20.5 & 40.5 & 16.5 & 7.5 \\
\hline
\end{tabular}

Note: $I$ is seismic intensity; $N$ is no damage; $\mathrm{Sl}$ is slight damage; $M$ is moderate damage; Se is serious damage; $C$ is collapse.

ment. In a real earthquake, the seismic intensity field of influence can be inferred from the four earthquake elements through the earthquake magnitude-intensity attenuation relationship. We will introduce this in the next section.

\subsubsection{Gridding DPM}

According to the Technical Rules for Earthquake Disaster Prediction and Related Information Management (GB/T19428-2003, 2003), building damage is classified into five categories in China: no damage, slight damage, moderate damage, serious damage and collapse. As shown in Fig. 1 and addressed above, the building exposure data are classified into four categories according to their structure and antiseismic characteristics.

In the CEA, the most widely used building vulnerability assessment method is Eq. (3) (Yin, 1995):

$D_{S j}(I)=P\left[D_{j} \mid I\right] B_{S}$,

where $D$ is the damage of a building, $I$ is seismic intensity, $S$ is the building type, $P\left[D_{j} \mid I\right]$ is the damage ratio of $S$ type building under $I$ intensity, which is a kind of DPM, $B_{S}$ is the total building area of $S$ type building and $j$ refers to the damage degree, which ranges from "no damage" to "collapse".

The DPM (referring to $P\left[D_{j} \mid I\right]$ ) is the key of the estimation. The DPM for this study come from Yin (1995) and is deduced from the hybrid method, which spatially covers the whole Chinese mainland area. In Table 1 we present part of the DPM for the B1-type building type as an example to explain its meaning. The earthquake disaster hazards of each region differs, which is represented in the earthquake intensity zoning map of China released by the CEA (China Earthquake Administration, 1996), shown in Fig. 3. In this map, possible maximal seismic intensity (seismic intensity with exceedance probability of $10 \%$ in the next 50 years) is used to depict the earthquake disaster hazard that the different regions of China face. If the possible maximal seismic intensity value is high in a region, it means great earthquake damage may occur in this region.

When people construct a building in a region with a high possible maximal intensity value, they need to ensure the

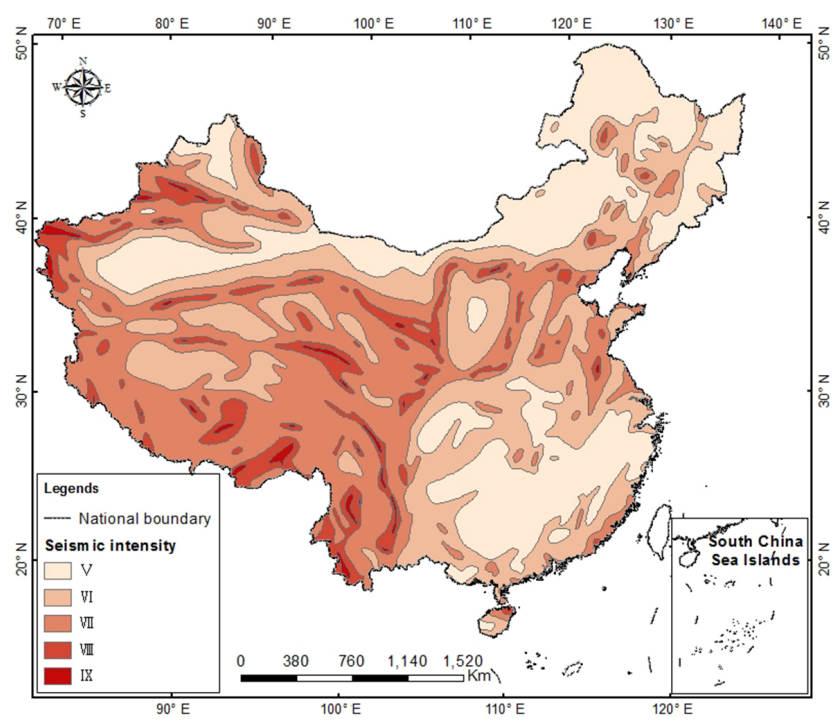

Figure 3. Earthquake intensity zoning map of China (third generation) (adapted from China Earthquake Administration, 1996).

building has high anti-seismic capacity, which is compulsory according to Chinese law. This also means the same type of building in different seismic intensity zones can have different anti-seismic abilities. Thus, the DPM values in different seismic intensity zones are different in Table 1.

According to the China Seismic Intensity Scale (GB/T17742-1999, 1999), seismic intensity in China ranges from I to XII. When the seismic intensity at a place caused by an earthquake is less than VI, no damage is considered to have occurred; at the upper end of the range, no earthquake of a seismic intensity of XII has been recorded in China. So in this study, the column values of the DPM range from VI to X, as shown in Table 1. Thus, the table values indicate the damage ratio; for example, when a high-rise building with a shear wall structure (B1 type) is struck by an earthquake of seismic intensity VIII and if it is located in a region of seismic intensity zone VI, the damage ratio for "no damage" is $40 \%$, but if it is located in an area of seismic intensity zone VII, the ratio is $55 \%$. 
Table 2. Value of the population density factor $f_{\mathrm{p}}$.

\begin{tabular}{lcccc}
\hline $\begin{array}{l}\text { Population } \\
\text { density }\end{array}$ & $\begin{array}{c}<50 / \\
\mathrm{km}^{2}\end{array}$ & $\begin{array}{c}50-200 / \\
\mathrm{km}^{2}\end{array}$ & $\begin{array}{c}200-500 / \\
\mathrm{km}^{2}\end{array}$ & $\begin{array}{c}>500 / \\
\mathrm{km}^{2}\end{array}$ \\
\hline$f_{\mathrm{p}}$ & 0.8 & 1.0 & 1.1 & 1.2 \\
\hline
\end{tabular}

The exposure data are in kilometre grid format, as in Fig. 1, so we grid the DPM for the convenience of the loss calculation with the support of a GIS.

The gridding of the DPM has two steps. (1) First, the DPM and earthquake intensity zoning map of China are linked (Fig. 3). The GIS spatial join operator can connect table data with spatial data. However, in this process the same ID values of the table and spatial data are needed. Likewise the same "seismic intensity" values are contained in both the DPM and the attribute table of the earthquake intensity zoning map. Then they have been selected as the connection ID values. Hence, the DPM tables are spatially associated with the vector map of the earthquake zoning of China. (2) The vector map is then converted to a grid map where the cell values depend on the DPM tables. The grid map has the same cell size with the exposure maps, as shown in Fig. 4.

\subsubsection{Building vulnerability assessment data generated in kilometre grid format}

After the gridding operation, the DPM is in a kilometre grid format. Then, Eq. (3) is realised by the map algebra, which is also in kilometre grid format. As a result of the spatial multiplication operation, a total of 100 layers are obtained, including four types of buildings, with five damage degrees (from "no damage" to "collapse") and five seismic intensity levels (from VI to X). For example, building damage data calculation process of the B1 type is displayed in Fig. 4, which is based on map algebra (spatial multiplication operation).

\subsubsection{Human loss data generation in kilometre grid format}

Many factors are related to deaths in an earthquake, including building damage, population density, the earthquake's occurrence time and available rescue countermeasures. Among them, building damage is the key factor (GB/T19428-2003, 2003).

A regression model is used in this study to estimate deaths (Ma and Xie, 2000):

$\log (\mathrm{RD})=9.0(\mathrm{RB})^{0.1}-10.07 ; \quad \mathrm{ND}=f_{t} f_{\mathrm{p}}(\mathrm{RD}) P$,

where ND is the number of deaths, RD is population death ratio, $\mathrm{RB}$ is the building collapse ratio, $P$ is the total number of population in the calculation area, $f_{t}$ is the time factor and $f_{\mathrm{p}}$ is the population density factor. Values of $f_{\mathrm{p}}$ are presented in Table 2 (Ma and Xie, 2000).
Table 3. Value of $f_{t}$ for night-time events.

\begin{tabular}{lccccc}
\hline Intensity & VI & VII & VIII & IX & X \\
\hline$f_{t}$ & 17 & 8 & 4 & 2 & 1.5 \\
\hline
\end{tabular}

The number of population in a building has a great influence on the loss of life in an earthquake, which is also influenced by the time of a day. According to the study of Ma and Xie (2000), with the seismic intensity increasing, the death of population at night and daytime are tend to equal, since evacuation of population from affected buildings becomes difficult even in daytime. The population death ratios between daytime and night are $0.06,0.13,0.25,0.43,0.74$ and 0.98 when the seismic intensity increase from VI to X. When the time factor $f_{t}$ is set as 1 in the daytime, then different values for the different seismic intensities at night are shown in Table 3 accordingly (Ma and Xie, 2000).

Using map algebra method, human loss estimation data are generated for the kilometre grid, which consists of two time periods (daytime and night-time) and five intensity ranges (from VI to XI), making a total of 10 layers.

Using this method, we developed a pre-calculated earthquake loss estimation data set in kilometre grid format, using the Python 2.7 language and ArcGIS Desktop 10.1 program. The ArcGIS file geodatabase was used to store and manage the loss data, including 100 building damage layers and 10 human loss layers. Some of these are shown in Fig. 5.

\subsection{Co-earthquake phase}

\subsubsection{Generating theoretical isoseismal map}

The isoseismal map is used to show lines of equally felt seismic intensity, which depict the seismic field of influence of the earthquake. We use a theoretical isoseismal map as a substitute for a real isoseismal map, which is produced from field investigations several days to several months after an earthquake.

The theoretical isoseismal map is generated in the following two steps.

1. Locating the earthquake position and determining the rupture direction of the fault zone causing the earthquake. For this, a Chinese nationwide fault zone distribution map is stored in the ArcGIS geodatabase in which the fault zone direction is recorded. Thus, after an earthquake we can quickly locate the earthquake position on this map and use the nearest fault zone direction as the fault rupture direction of the earthquake.

2. Then, the earthquake magnitude-intensity attenuation relationship is used to generate isoseismal lines from seismic intensity VI to its maximum theoretical intensity. Spatially, the theoretical earthquake intensity is an 


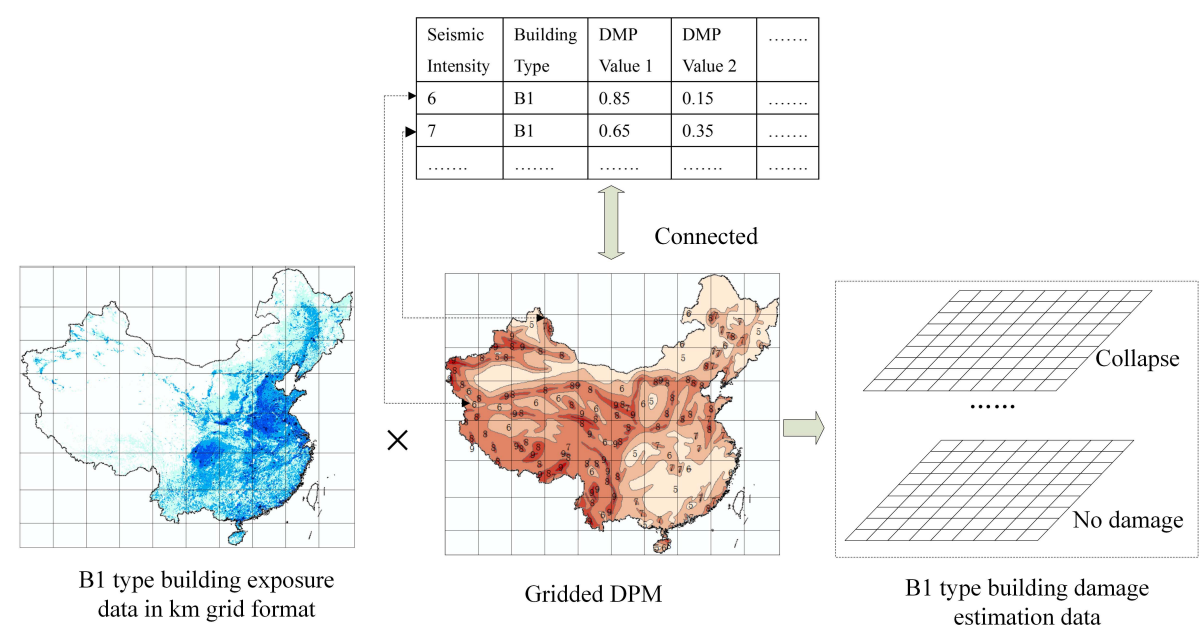

Figure 4. Building vulnerability data calculation process of the B1 type based on map algebra.
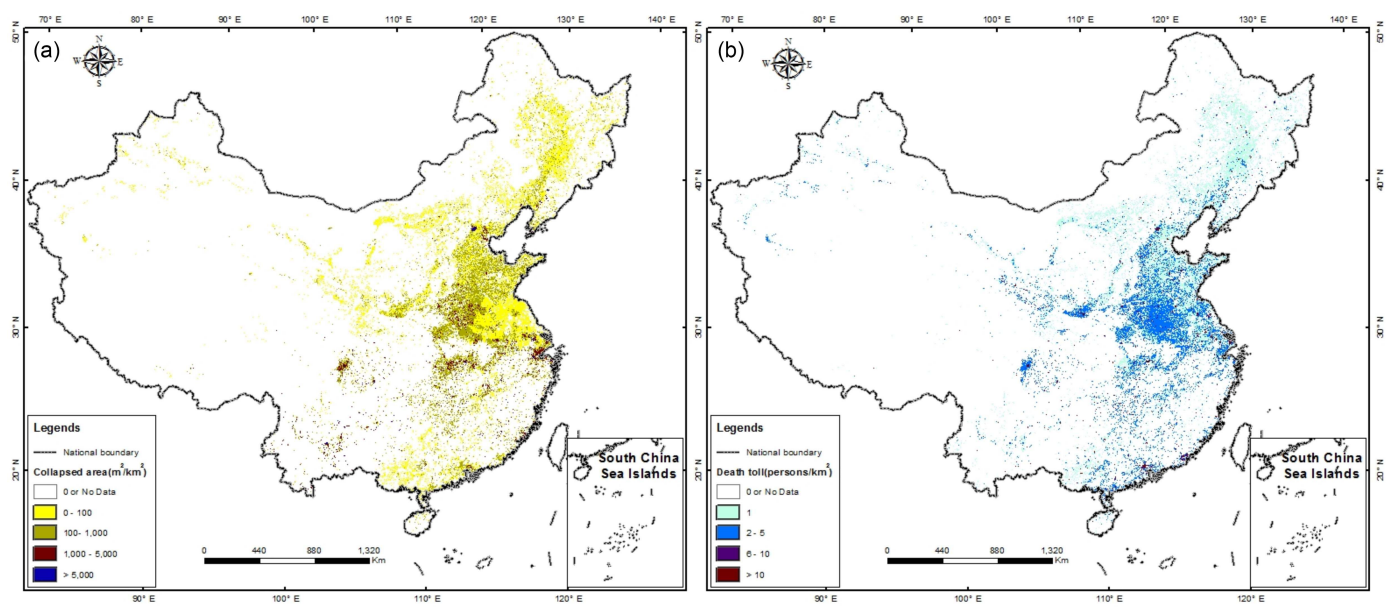

Figure 5. Example of the pre-calculated earthquake loss estimation data set: (a) "collapse" under intensity $X$ of B1 type building; (b) human losses due to intensity $X$ in daytime.

ellipse. Equations (5) and (6) are the most widely used for establishing the attenuation relationship, fitting eastern China and western China separately. The east longitude $107.5^{\circ}$ is considered the dividing line between eastern China and western China (China Earthquake Administration, 2010). If the longitude of the epicentre is greater than $107.5^{\circ}$, then Eq. (5) will be used. Otherwise, Eq. (6) is used:

$I_{\alpha}=6.046+1.480 M_{\mathrm{S}}-2.081 \ln \left(R_{\alpha}+25\right)$

$I_{\beta}=2.617+1.435 M_{\mathrm{s}}-1.441 \ln \left(R_{\beta}+7\right)$,

$I_{\alpha}=5.643+1.538 M_{\mathrm{S}}-2.109 \ln \left(R_{\alpha}+25\right)$

$I_{\beta}=2.941+1.303 M_{\mathrm{s}}-1.494 \ln \left(R_{\beta}+7\right)$,

where $I_{\alpha}$ and $I_{\beta}$ are the average intensity around the ellipse long axis and short axis, $R_{\alpha}$ and $R_{\beta}$ are the short and long axis of the ellipse and $M_{\mathrm{S}}$ is the earthquake magnitude. The distance unit is kilometres.

Equations (5) and (6) are transformed to Eqs. (7) and (8). Once $M_{\mathrm{s}}$ and $I_{\alpha}\left(I_{\alpha}\right.$ always equates to $\left.I_{\beta}\right)$ are determined, the length of the short axis $\left(R_{\alpha}\right)$ and long axis $\left(R_{\beta}\right)$ of the ellipse can be calculated.

$R_{\alpha}=e^{\left(6.046+1.480 M_{\mathrm{s}}-I_{\alpha}\right) / 2.081}-25$
$R_{\beta}=e^{\left(2.617+1.435 M_{\mathrm{s}}-I_{\beta}\right) / 1.441}-7$

$R_{\alpha}=e^{\left(5.643+1.538 M_{\mathrm{s}}-I_{\alpha}\right) / 2.109}-25$

$R_{\beta}=e^{\left(2.941+1.303 M_{\mathrm{s}}-I_{\beta}\right) / 1.494}-7$

Then the theoretical isoseismal map of the earthquake can be quickly generated. As an example, the isoseismal map for the 2013 Minxian earthquake is shown in Fig. 6. More in- 
Table 4. Basic information on the test cases.

\begin{tabular}{llccc}
\hline $\begin{array}{l}\text { Case } \\
\text { ID }\end{array}$ & $\begin{array}{l}\text { Earthquake } \\
\text { name/location }\end{array}$ & Earthquake time & $\begin{array}{c}\text { Magnitude } \\
\left(M_{\mathrm{S}}\right)\end{array}$ & $\begin{array}{c}\text { Focal } \\
\text { depth } \\
(\mathrm{km})\end{array}$ \\
\hline E1 & $\begin{array}{l}\text { Wenchuan, in Sichuan } \\
\left(31.0^{\circ} \mathrm{N}-103.4^{\circ} \mathrm{E}\right)\end{array}$ & 12 May 2008 14:28 & 8.0 & 14 \\
E2 & $\begin{array}{l}\text { Yiliang, in Yunnan } \\
\left(27.6^{\circ} \mathrm{N}-104.0^{\circ} \mathrm{E}\right)\end{array}$ & 7 Sep 2012 11:19 & 5.7 & 14 \\
E3 & $\begin{array}{l}\text { Minxian, in Gansu } \\
\left(34.5^{\circ} \mathrm{N}-104.2^{\circ} \mathrm{E}\right)\end{array}$ & 22 Jul 2013 07:45 & 6.6 & 20 \\
E4 & $\begin{array}{l}\text { Ludian, in Yunnan } \\
\left(27.1^{\circ} \mathrm{N}-103.3^{\circ} \mathrm{E}\right)\end{array}$ & 3 Aug 2014 16:30 & 6.5 & 12 \\
\hline
\end{tabular}

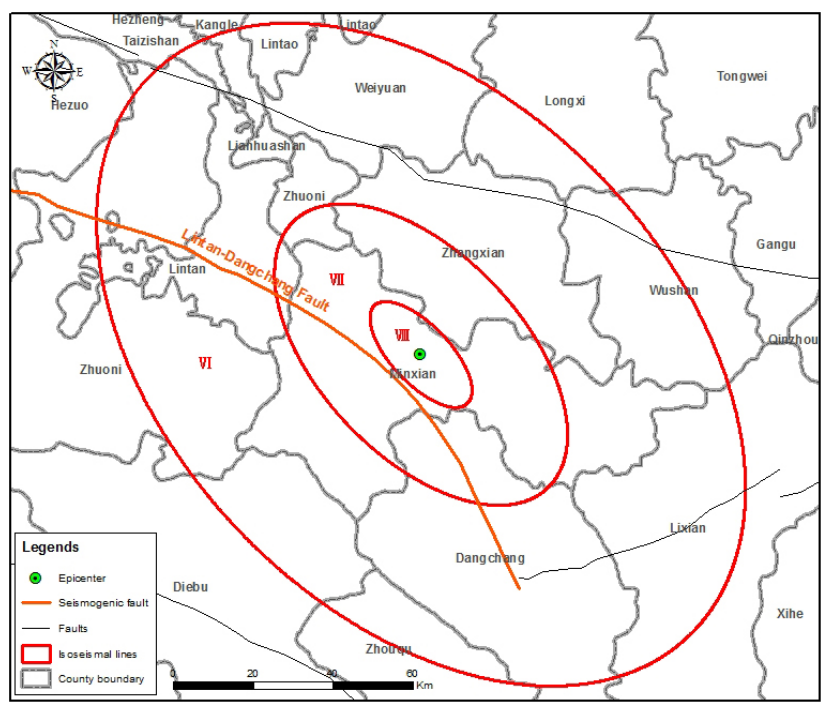

Figure 6. Theoretic isoseismal map of the Minxian earthquake (detailed information about the Minxian earthquake is listed in the Table 4).

formation about the Minxian earthquake is listed in Table 4 (event E3).

\subsubsection{Extraction of statistics on disaster loss}

In this stage, the disaster loss calculation essentially becomes a spatial extraction of statistics of pre-calculated disaster loss estimation data, according to the spatial distribution of the theoretical isoseismal map. The steps are as follows:

1. First, we separately build isoseismal polygons according the seismic intensity value. These isoseismal polygons are then converted into raster (kilometre grid) format, with the intensity value being their attribute value.

2. Then, the loss data associated with different seismic intensities are retrieved from the pre-calculated loss estimation data set. The isoseismal polygon with a certain intensity (for example intensity VI) is used as spatial

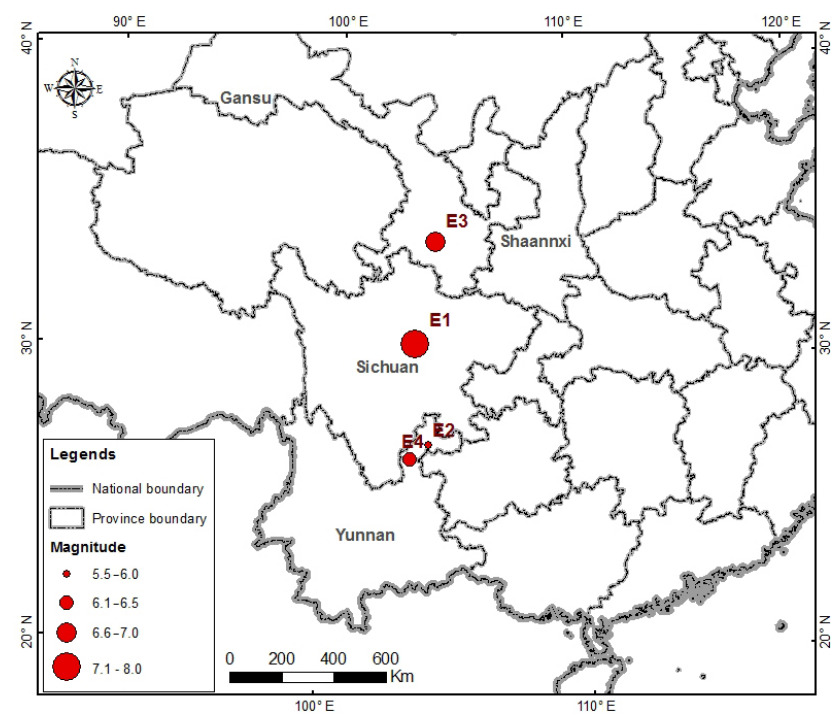

Figure 7. The locations of the four earthquakes used as test cases (see Table 4).

query condition to extract the disaster data within the polygon from the retrieved data. We repeat the query and extraction to the maximum seismic intensity.

3. The human losses from each queried result are counted.

4. The human losses are summed to obtain the final losses of the earthquake.

\section{Validation and discussion}

\subsection{Validation}

In order to validate and test the effectiveness of the precalculation loss estimation data and the corresponding loss estimation method, we selected four destructive earthquakes that occurred on the Chinese mainland as test cases, their locations shown in Fig. 7 with some details presented in Table 4 . 
Table 5. Comparison of calculation speed and accuracy for the test cases.

\begin{tabular}{|c|c|c|c|c|c|}
\hline Performance & Estimation method & E1 & E2 & E3 & E4 \\
\hline \multirow[t]{2}{*}{$\begin{array}{l}\text { Time } \\
\text { consumed }\end{array}$} & $\begin{array}{l}\text { No grid data support } \\
\text { (traditional method) }\end{array}$ & $27 \mathrm{~min}$ & $7.8 \mathrm{~min}$ & $8.7 \mathrm{~min}$ & $8.5 \mathrm{~min}$ \\
\hline & $\begin{array}{l}\text { Grid data support } \\
\text { (two-phase method) }\end{array}$ & $38 \mathrm{~s}$ & $26 \mathrm{~s}$ & $30 \mathrm{~s}$ & $29 \mathrm{~s}$ \\
\hline \multirow{2}{*}{$\begin{array}{l}\text { Human loss } \\
\text { estimation } \\
\text { accuracy }\end{array}$} & $\begin{array}{l}\text { No grid data support } \\
\text { (traditional method) }\end{array}$ & $\begin{array}{l}170739 \\
(246.7 \%)\end{array}$ & $\begin{array}{l}31 \\
(38.8 \%)\end{array}$ & $\begin{array}{l}68 \\
(71.6 \%)\end{array}$ & $\begin{array}{l}237 \\
(38.4 \%)\end{array}$ \\
\hline & $\begin{array}{l}\text { Grid data support } \\
\text { (two phase method) }\end{array}$ & $\begin{array}{l}63093 \\
(91.1 \%)\end{array}$ & $\begin{array}{l}75 \\
(93.8 \%)\end{array}$ & $\begin{array}{l}70 \\
(73.7 \%)\end{array}$ & $\begin{array}{l}369 \\
(59.8 \%)\end{array}$ \\
\hline $\begin{array}{l}\text { Real human } \\
\text { loss }\end{array}$ & & 69227 & 80 & 95 & 617 \\
\hline
\end{tabular}

As addressed before, Fig. 1 shows the exposure data (building and population) as a dasymetric map in kilometre grid format. In order to compare our results with the administrative unit-based exposure data support loss estimation method, we used the city as the statistics unit and summed up the grid values of the dasymetric map within a city range to generate the administration unit-based exposure data.

The traditional earthquake loss estimation method was used for the test, which includes the following steps: (1) according to the four earthquake elements (Table 4), a theoretical isoseismal map is generated; (2) according to the spatial distribution of seismic intensity in the isoseismal map, the building damage is separately calculated by the DPM; and (3) the human losses are calculated based on building damage. In this estimation process, the disaster losses are not precalculated before the earthquake, and all disaster losses are calculated on the fly.

In the case studies, the building damage estimation and human loss estimation are based on identical calculation formulae, as shown in Eqs. (3) to (6). We used an identical hardware environment for the two estimations, which was used to realise the calculation process: Intel Core2 Quad CPU Q9550 at 2.83 GHz, 4.00 GB RAM, Windows 7 Pro 32-Bit with SP1, Python 2.7 and ArcGIS Desktop 10.1.

We selected human losses as the estimation aim. There are three reasons for this selection: (1) human losses are more important than building damage losses for earthquake emergency response; (2) human loss estimation appears to be more sophisticated and time-consuming since it is based on building damage loss estimation; and (3) real human loss values arising from the actual earthquakes are relatively simple to collect and are released by the government at all levels. Thus, real human loss values are more authentic and accurate than the building losses in these actual earthquakes.

In these case studies, we mainly focused on the evaluation accuracy and especially speed, since for earthquake emergency response and rescue, speed is more important than accuracy. The results are shown in Table 5.

\subsection{Discussion}

The experiment shows that the earthquake disaster loss estimation method explored in this study can significantly improve the estimation speed. The disaster estimation can be done within a single minute on a normal personal computer, even when facing a huge earthquake like the Wenchuan earthquake $\left(M_{\mathrm{S}}=8.0\right)$. The reason for this quick speed is the pre-calculation of the disaster loss before the earthquake's occurrence. So after the earthquake, the disaster estimation literally becomes the disaster loss spatial statistics according to the seismic intensity field. The pre-calculated disaster loss method benefits from the dasymetric map approach. Without the support of the kilometre grid format exposure data, it would be hard to perform a meaningful pre-calculated disaster loss estimation. The other benefit of this pre-calculation method is that we can directly estimate the loss of lives. However, in the traditional method, it is necessary to go through the building damage estimation on the fly before the human loss estimation.

However, this earthquake disaster estimation method also greatly depends on dasymetric exposure data, which increases the difficulty in the production of the exposure data. Although the dasymetric population data development method and product are increasingly popular and easy to make available, it is still not simple to obtain appropriate data in many countries and regions, especially in some undeveloped regions. Meanwhile, the compilation of areal exposure data and the corresponding methods are lacking even in developed countries (Han et al., 2013). In this study, we pre-calculated the earthquake losses to improve the estimation speed, but flexibility was also lost in the disaster loss estimation. The updating of the disaster exposure data, calculation parameters or calculation formulae will result in the need for the whole pre-calculated disaster loss estimation data to be revised. Furthermore, the pre-calculation disaster loss estimation data will consume some hardware storage: in our study, 5.98 GB was used for the storage of these pre- 


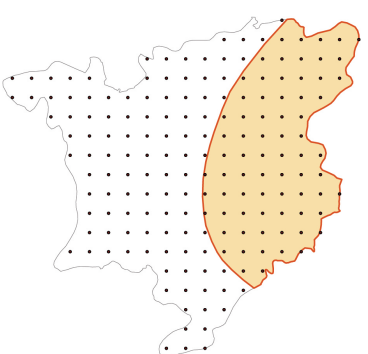

(a)

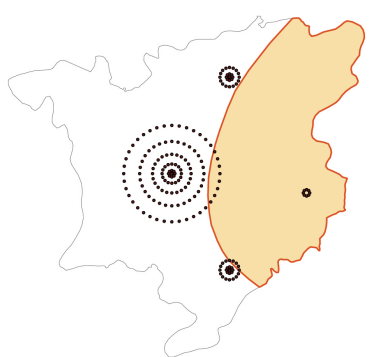

(b)

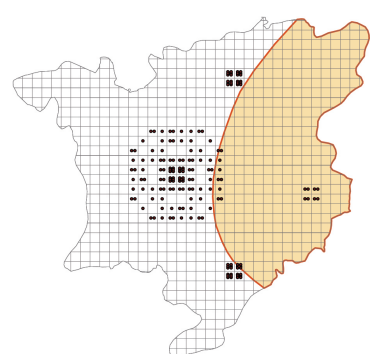

(c)

Figure 8. The representation of the spatial distribution of population exposure data. The points represent the population distribution. The area surrounded by the red boarder represents the affected disaster area within an administration unit. (a) Average distribution inside the whole administration unit; (b) actual distribution according to settlements; (c) gridded distribution supported by the dasymetric map approach.

calculated disaster loss estimation data (building damage and population loss in ArcGIS file geodatabase format). However, with the ongoing development of computer hardware, it does not seem a big issue considering the improvement in estimation speed.

As shown from the experiment results, the accuracy of disaster loss estimation of the studied method is also improved. The reason is the spatial disparity considered in the dasymetric exposure data. Taking population distribution as an example, if just part of an administration unit has been affected by an earthquake disaster, how many populations in this unit should be used for loss estimation calculation? The administration unit supported method assumes the exposure data averagely distributed inside the census units, as shown in Fig. 8a, and Eq. (9) is used for determining the population in the disaster loss calculation.

Pop $_{\text {inf }}=\left(\frac{\text { Area }_{\text {inf }}}{\text { Area }_{\text {county }}}\right) \cdot$ Pop $_{\text {county }}$,

where Popinf is the population affected by the disaster, Area $_{\text {inf }}$ is the area affected in the county (the area of the yel-

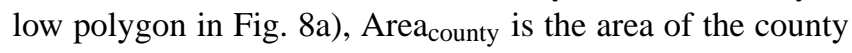
and Pop county is the population of the county.

However, this assumption is inappropriate because population is not evenly distributed throughout the administration unit. Generally, people tend to live around the main settlement points such as the village or city centre. Figure $8 \mathrm{~b}$ shows the real population distribution, in which case only a very small proportion of the population are located in the disaster affected area. Hence, Eq. (9) will produce a large error in the human loss estimation. By contrast, dasymetric exposure population data provide a more realistic description, as shown in Fig. 8c. The population data used for disaster loss calculation are based on the sum of all the influenced population grids. Therefore, it is easy to improve upon the estimation accuracy of an earthquake whose exposure data in the affected area have a high spatial disparity.

The experiment reveals that the estimation results from both methods for the Ludian earthquake (Event E4, Table 4) has large deviations from the actual losses. The reason is that the human loss estimation considers building damage as the only contributing factor. However, $87 \%$ of Ludian County is mountainous, and after the earthquake serious secondary geological hazards occurred, such as landslides. Field investigations after the Ludian earthquake showed that about onethird of human losses were caused by such secondary geological hazards (China Earthquake Administration, 2015). For the Minxian earthquake, there is a similar situation, as parts of villages were even covered by debris flow.

The deviations found in all of the four cases arise from several reasons. Identical theoretical isoseismal maps were used in both the traditional estimation method and in the twophase method. We believe the inconsistency between the theoretical isoseismal map and the actual isoseismal map is one of reasons that contributes to the deviations. Because the actual isoseismal map of an earthquake is usually plotted several days to several months after the field investigations, we use the theoretical isoseismal map to substitute for the actual one in the disaster estimation for emergency response. Theoretical isoseismal maps are established from Eqs. (7) and (8), which are deduced from regression analysis of historical isoseismal maps. Although the inconsistency is well known in Chinese earthquake engineering field, the theoretical isoseismal map is still widely used for co-earthquake disaster estimation for two reasons: (1) there is no better alternative and (2) the deviation caused by this inconsistency is limited (China Earthquake Administration, 2015). Shakemap has good potential in solving this problem, but it is currently still under development in China.

Meanwhile, the accuracy of the kilometre grid exposure data has a great influence on the two-phase disaster estimation method. Some dasymetric map approaches or exposure data are recommended, such as the regression method supported by LULC data, LandScan data set (http://web.ornl. gov/sci/landscan/).

The pre-calculated kilometre grid-based disaster loss estimation data not only improve upon the disaster estimation speed and accuracy but also generate extra value in earthquake emergency response. We take the Wenchuan earthquake as an example, where the earthquake disaster loss es- 


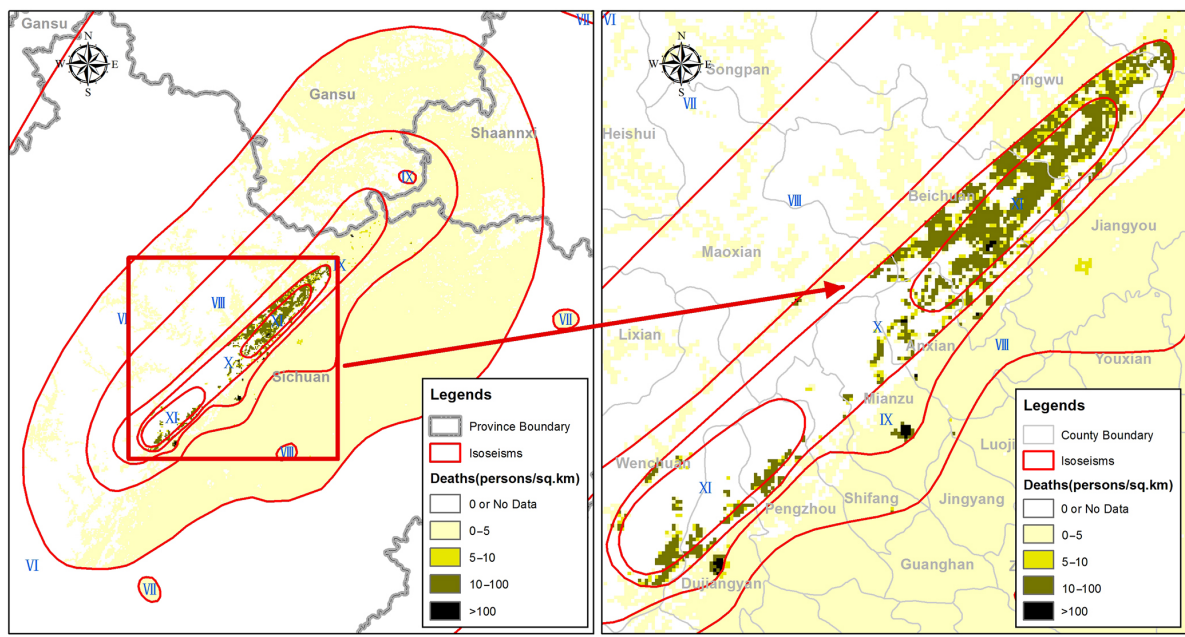

Figure 9. Predictions of the spatial distribution of potential deaths for the Wenchuan earthquake.

timation results represent not just the number of deaths, like the traditional method. They also provide the spatial distribution of the possible loss of lives, as shown in Fig. 9. This provides useful guidance to disaster area emergency rescue actions and for the emergency evacuation of people.

\section{Conclusions}

The rapid and accurate estimation of earthquake disaster losses in the period up to $2 \mathrm{~h}$ after an earthquake is crucial for earthquake emergency response and rescue (Nie et al., 2012). It is therefore the key motivation for this study. The core contribution of this study is a new earthquake disaster loss estimation method for earthquake emergency response based on dasymetric exposure data. The method consists of two phases: a pre-earthquake phase and a co-earthquake phase. In the pre-earthquake phase, disaster losses have been precalculated and stored as a dasymetric map in kilometre grid format, thereby benefiting from the areal format of exposure data. Then, in the co-earthquake phase, the calculation of disaster loss is based on the spatial statistics of the precalculated disaster loss estimation data combined with the seismic intensity field.

Compared to other studies, this method can not only improve the speed and accuracy of earthquake disaster estimation for co-earthquake response but also provide the spatial distribution of possible deaths and building damage (for example, the PAGER system only provides the risk level for emergency response). The spatial distribution information is beneficial to earthquake disaster relief decision-making and rescue actions. Moreover, the corresponding pre-calculated disaster loss estimation data can be used for earthquake disaster risk analysis before an earthquake's occurrence.

Four recent real earthquakes that have occurred on the Chinese mainland were selected as the experimental cases to validate the new method, by means of the estimation of deaths. We conclude that the proposed estimation method is effective in improving the speed and accuracy of earthquake loss estimation. The estimation time is significantly reduced, even for a huge earthquake such as the Wenchuan earthquake using a normal personal computer. Although improvements have been found in the accuracy of the proposed estimation method, deviations between estimated losses and real losses are also found in the Ludian and Minxian earthquakes, which cannot be overlooked. This indicates that serious consideration should be given to how the secondary geological disaster impact of earthquakes influences the human loss estimation, especially for mountainous areas, which are widespread in south-western China, which is also the most frequent area of earthquake occurrences in China.

Currently, the pre-calculated earthquake loss estimation areal data and the corresponding two-phase loss estimation method are used by the CEA. In the future, we will explore the influence of secondary geological disasters on the estimation of human losses in mountainous areas. The automatic generation of earthquake response countermeasures using earthquake emergency response knowledge (Xu et al., 2014) from estimated earthquake disaster losses is another direction of study that will be pursued in the future.

Acknowledgements. This work was supported in part by grants from the Special Fund for Basic Scientific Research Operations of the Institute of Geology, CEA (grant no. IGCEA1506), Jiangsu Surveying, Mapping and Geoinformation Science Research Project (grant no. JSCHKY201506), Open Research Fund Program of Shenzhen Key Laboratory of Spatial Smart Sensing and Services (Shenzhen University) (grant no. 201404), the National Key Technology R \& D Programme of China (grant no. 2012BAK15B06) and the National Natural Science Foundation of China (Grant No. 40901272). 
The authors would like to express their appreciation to Scott Miles at Western Washington University and Wenxia Tan at Central China Normal University for their valuable help. The authors also wish to thank the editor and the three referees for their comments and suggestions that greatly improved this manuscript.

Edited by: S. Tinti

Reviewed by: K. Fleming and two anonymous referees

\section{References}

Alahmadi, M., Atkinson, P., and Martin, D.: Estimating the spatial distribution of the population of Riyadh, Saudi Arabia using remotely sensed built land cover and height data, Comput. Environ. Urb., 41, 167-176, 2013.

Alam, M. N., Tesfamariam, S., and Alam, M. S.: GIS-based seismic damage estimation: case study for the City of Kelowna, BC, Nat. Hazards Rev., 14, 66-78, 2013.

Anagnos, T., Rojahn, C., and Kiremidjian, A. S.: NCEER-ATC joint study on fragility of buildings, Techn. Rep. NCEER 95-0003, State Univ. of NY, Buffalo, 1995.

Armenakis, C: Estimating spatial disaster risk in urban environments, Geomat. Nat. Hazards Risk, 4, 289-298, 2013.

ATC: Earthquake damage evaluation data for California, ATC13 Report, Applied Technology Council, Redwood City, California, 1985.

Balk, D. and Yetman, G.: The global distribution of population: evaluating the gains in resolution refinement, Center for International Earth Science Information Network (CIESIN), Columbia University, New York, 2004.

Chakraborty, J., Tobin, G. A., and Montz, B. E.: Population evacuation: assessing spatial variability in geophysical risk and social vulnerability to natural hazards, Nat. Hazards Review, 6, 23-33, 2005.

Chen, K. P., McAneney, J., Blong, R., Leigh, R., Hunter, L., and Magill, C.: Defining area at risk and its effect in catastrophe loss estimation: a dasymetric mapping approach, Appl. Geogr., 24, 97-117, 2004.

Chen, Z. T., Li, Z. Q., Ding, W. X., and Han, Z. H.: Study of Spatial Population Distribution in Earthquake Disaster Reduction - A Case Study of 2007 Ning'er Earthquake, Technol. Earthq. Disast. Prevent., 7, 273-284, 2012.

China Earthquake Administration: Earthquake intensity zoning map of China, 3rd Edn., Seismological Press, Beijing, 1996.

China Earthquake Administration: Report on earthquake emergency disaster information recognition and evaluation technologies, Institute of Geology, China Earthquake Administration, Beijing, China, 1253 pp., 2010.

China Earthquake Administration: Report on earthquake disaster information service and emergency response decision-making support platform, Institute of Geology, China Earthquake Administration, Beijing, China, 412 pp., 2015.

CIESIN - Center for International Earth Science Information Network: Global Rural Urban Mapping Project (GRUMP), Alpha Version: Urban extents, Center for International Earth Science Information Network (CIESIN), Columbia University, New York, 2004.
Coburn, A. and Spence, R.: Earthquake Protection, 2nd edition, John Wiley and Sons, West Sussex, England, 2002.

Dmowska, A. and Stepinski, F. T.: High resolution dasymetric model of US demographics with application to spatial distribution of racial diversity, Appl. Geogr., 53, 417-426, 2014.

Dobson, J. E., Bright, E. A., Coleman, P. R., Durfee, R. C., and Worley, B. A.: LandScan: a global population database for estimating populations at risk, Photogram. Eng. Remote Sens., 66, 849-857, 2000.

Dymiotis, C, Kappos, A. J., and Chryssanthopoulos, M. C.: Seismic reliability of $\mathrm{R} / \mathrm{C}$ frames with uncertain drift and member capacity, J. Str. Eng. ASCE, 125, 1038-1047, 1999.

Earthquake Emergency Rescue Department, China Earthquake Administrator: Earthquake Emergency Response, Seismological Press, Beijing, 2004.

Eleftheriadou, A. K. and Karabinis, A. I.: Development of damage probability matrices based on Greek earthquake damage data, Earthq. Eng. Eng. Vib., 10, 129-141, 2011.

FEMA: HAZUSMH MR4 Technical manual, Washington, DC: Federal Emergency Management Agency, available from: https://www.fema.gov/media-library/assets/documents/24609? id=5120 (last access: 10 November 2015), 2003.

GB/T17742-1999: China seismic intensity scale, General Administration of Quality Supervision, Inspection, and Quarantine of P R China, 1999.

GB/T19428-2003: Technology rule of earthquake disaster prediction and related information management, General Administration of Quality Supervision, Inspection, and Quarantine of P R China, 2003.

Han, Z. H., Li, Z. Q., Chen, Z. T., and Ding, W. X.: Population, housing statistics data spatialization research in the application of rapid earthquake loss assessment: a case of Yiliang earthquake, Seismol. Geol., 35, 894-906, 2013.

Hassanzadeh, R., Zorica, N. B., Alavi, R. A., Norouzzadeh, M., and Hodhodkian, H.: Interactive approach for GIS-based earthquake scenario development and resource estimation (Karmania hazard model), Comput. Geosci., 51, 324-338, 2013.

Jia, P., Qiu, Y. L., and Gaughan, E. A.: A fine-scale spatial population distribution on the high-resolution gridded population surface and application in Alachua County, Florida, Appl. Geogr., 50, 99-107, 2014.

Jiang, D., Yang, X. H., Wang, N. B., and Liu, H. H.: Study on Spatial Distribution of Population based on Remote Sensing and GIS, Adv. Earth Sci., 17, 734-738, 2002.

Kappos, A. J., Panagopoulos, G., Panagiotopoulos, C., and Penelis, G.: A hybrid method for the vulnerability assessment of R/C and URM buildings, Bull. Earthq. Eng., 4, 391-413, 2006.

Karimzadeh, S., Miyajima, M., Hassanzadeh, R., Amiraslanzadeh, R., and Kamel, B.: A GIS-based seismic hazard, building vulnerability and human loss assessment for the earthquake scenario in Tabriz, Soil Dyn. Earthq. Eng., 66, 263-280, 2014.

Langford, M.: Rapid facilitation of dasymetric-based population interpolation by means of raster pixel maps, Comput. Environ. Urb., 31, 19-32, 2007.

Lin, J., Cromley, R., and Zhang, C.: Using geographically weighted regression to solve the areal interpolation problem, Ann. GIS, 17, 1-14, 2011.

Ma, Y. H. and Xie, L. L.: Methodologies for assessment of earthquake causality, Earthq. Eng. Eng. Vib., 20, 140-147, 2000. 
Martin, D.: Directions in population GIS, Geogr. Compass, 5, 655665,2011

Mebarki, A., Boukri, M., Laribi, A., Farsi, M., Belazougui, M., and Kharchi, F.: Seismic vulnerability: theory and application to Algerian buildings, J. Seismol., 18, 331-343, 2014.

Miao, C. G. and Nie, G. Z.: Exploration on mode of earthquake emergency command, J. Nat. Disast., 13, 48-54, 2004.

Mocormack, C. and Rad, F. N.: Earthquake loss estimation methodology for buildings based on ATC-13 and ATC-21, Earthquake Spectra, 1, 605-621, 1997.

Nadim, F., Moghtederi-zadeh, M., Lindholm, C., Anderson, A., Remseth, S., Bolourchi, M., Mokhtari, M., and Tvedt, E.: The Bam earthquake of 26 December 2003, B. Earthq. Eng., 2, 119153, 2004.

Nie, G. Z., Chen, J. Y., Li, Z. Q., Su, G. W., Gao, J. G., and Liu, H. M.: The construction of basic database for earthquake emergency response, Earthquake, 22, 105-112, 2002.

Nie, G. Z., An, J. W., and Deng, Y.: Advances in earthquake emergency disaster service, Seismology and Geology, 34, 782-791, 2012.

NRC - National Research Council: The Impacts of Natural Disasters: A Framework for Loss Estimation, National Academy Press, Washington, D.C., 1999.
Panahi, M., Rezaie, F., and Meshkani, S. A.: Seismic vulnerability assessment of school buildings in Tehran city based on AHP and GIS, Nat. Hazards Earth Syst. Sci., 14, 969-979, doi:10.5194/nhess-14-969-2014, 2014.

Thieken, A. H., Müller, M., Kleist, L., Seifert, I., Borst, D., and Werner, U.: Regionalisation of asset values for risk analyses, Nat. Hazards Earth Syst. Sci., 6, 167-178, doi:10.5194/nhess-6-1672006, 2006.

Whitman, R. V., Reed, J. W., and Hong, S. T.: Earthquake damage probability matrices, www.iitk.ac.in/nicee/wcee/article/5_vol2_ 2531.pdf (last access: 18 December 2015), 1973.

$\mathrm{Xu}$, J. H., Nie, G. Z., and Xu, X.: A digital social network for rapid collection of earthquake disaster information, Nat. Hazards Earth Syst. Sci., 13, 385-394, doi:10.5194/nhess-13-385-2013, 2013.

Xu, J. H., Nyerges, L. T., and Nie, G. Z: Modeling and representation for earthquake emergency response knowledge: perspective for working with geo-ontology, Int. J. Geogr. Inf. Sci., 28, 185205, 2014.

Yin, Z. Q.: Earthquake Disaster and Loss Prediction Method, Seismological Press, Beijing, 1995. 